BUDGETING : Journal of Business, Management and Accounting

Volume 2, Nomor 1, Desember 2020

e-ISSN: $2715-2480$

p-ISSN: 2715-1913

DOI : https://doi.org/10.31539/budgeting.v2i1.1736

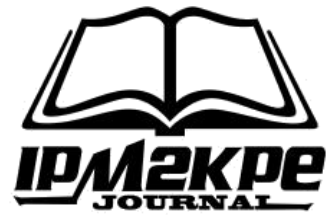

\title{
PENINGKATAN KEPUASAN PELANGGAN MELALUI EXPERIENTIAL MARKETING DAN NILAI PELANGGAN
}

\author{
Anggara Putra Munggaran ${ }^{1}$, R. Deni Muhammad Danial ${ }^{2}$, Faizal Mulia Z. ${ }^{3}$ \\ Universitas Muhammadiyah Sukabumi ${ }^{1,2,3}$ \\ anggarapm97@gmail.com ${ }^{1}$
}

\begin{abstract}
ABSTRAK
Tujuan penelitian ini adalah untuk menganalisis pengaruh experiential marketing dan nilai pelanggan terhadap kepuasan pelanggan pada CV. Yukas Family Kabupaten Sukabumi. Metode yang digunakan dalam penelitian ini adalah metode deskriptif asosiatif. Teknik analisis data yang digunakan adalah regresi linier berganda. Hasil penelitian menunjukkan bahwa berdasarkan garis kontinum, experiential marketing di CV. Yukas Family Kabupaten Sukabumi melalui dimensi sense, feel, think, act dan relate memiliki nilai yang tinggi dalam meningkatkan kepuasan konsumen. Nilai pelanggan berupa nilai emosional, nilai sosial, nilai kualitas dan nilai biaya sebagai dimensi memiliki garis kontinum yang berada pada kategori sedang. Kemudian kepuasan pelanggan berdasarkan dimensi kualitas produk, harga produk, kualitas layanan, emosi, biaya dan kenyamanan juga termasuk dalam kategori sedang. Simpulan, pelanggan merasa puas dengan penerapan experiential marketing, nilai pelanggan, kualitas produk, harga produk, kualitas layanan, emosi, biaya dan kenyamanan. Secara umum, experiential marketing dan nilai pelanggan memiliki pengaruh terhadap kepuasan pelanggan di CV. Yukas Family di Kabupaten Sukabumi.
\end{abstract}

Kata Kunci: Experiential Marketing, Nilai Pelanggan, Kepuasan Pelanggan

\begin{abstract}
The purpose of this study was to analyze the effect of experiential marketing and customer value on customer satisfaction at CV. Yukas Family, Sukabumi Regency. The method used in this research is associative descriptive method. The data analysis technique used is multiple linear regression. The results showed that based on the continuum line, experiential marketing at CV. The Yukas family of Sukabumi Regency through the dimensions of sense, feel, think, act and relate has a high value in increasing customer satisfaction. Customer value in the form of emotional value, social value, quality value and cost value as dimensions has a continuum line which is in the medium category. Then customer satisfaction based on the dimensions of product quality, product price, service quality, emotion, cost and convenience is also included in the medium category. In conclusion, customers are satisfied with the application of experiential marketing, customer value, product quality, product price, service quality, emotion, cost and convenience. In general, experiential marketing and customer value have an influence on customer satisfaction at CV. Yukas family in Sukabumi Regency.
\end{abstract}

Keywords: Experiential Marketing, Customer Value, Customer Satisfaction 


\section{PENDAHULUAN}

Perkembangan pembangunan di Indonesia saat ini sangat pesat, terutama pembangunan perusahaan/industri yang menyebabkan seorang pelaku usaha harus bisa mengeluarkan inovasi-inovasi baru dan mengkonsep perusahaannya agar dapat terus maju dan berkembang dengan menghasilkan sebuah produk atau jasa yang dapat membuat para pelanggan merasa puas dan bisa memberikan pengalaman yang positif bagi pelanggan.

Pembangunan perusahaan/industri di Kabupaten Sukabumi sangat banyak, sehingga pemilik usaha harus berusaha semaksimal mungkin untuk mempertahankan pelanggannya karena pelanggan merupakan aset perusahaan. Oleh karena itu untuk mengatasi penurunan pelanggan karena berpindah ke perusahaan pesaing, perusahaan harus memberikan sebuah pelayanan untuk memberikan sebuah kepuasan terhadap pelanggan dengan memenuhi keinginan dan kebutuhan pelanggan. Dengan memberikan kepuasan terhadap pelanggan, pelanggan pun akan melakukan pembelian ulang pada perusahaan tersebut. Masyarakat di Sukabumi terutama di daerah Nyalindung banyak melakukan pembangunan berupa rumah, pabrik, gedung dan sebagainya pada tahun 2014 sampai 2018. Hal ini membuka peluang bagi perusahaan material bangunan.

Zaman sekarang yang serba parktis membuat masyarakat pun ingin serba praktis, terutama dalam pembangunan rumah, gedung dan lain-lain. Masyarakat ingin menggunakan produk yang praktis seperti rangka atap rumah yang terbuat dari baja ringan dan genteng metal. Selain rangka atap rumah atau gedung, ada juga pagar minimalis dari besi, rolling door dan banyak lagi jenis bahan-bahan pembangunan yang praktis. Dampak positif dengan adanya produk bahan-bahan bangunan yang praktis seperti baja, besi, almunium dan lain-lain akan mengurangi penggunaan bahan alami seperti pohon-pohon yang ada di hutan. Hal tersebut dapat mengurangi terjadinya hutan gundul karena banyaknya penebangan pohon.

Pembangunan dengan menggunakan bahan-bahan praktis dapat mempersingkat waktu pembangunan serta tidak banyak mengeluarkan biaya jasa dalam pembangunan tersebut. Produk ini mempunyai kekuatan yang sangat baik sehingga tidak mudah rusak dalam jangka waktu minimal 10 tahun. Untuk memenangkan persaingan, perusahaan harus mampu memberikan kepuasan kepada para pelanggannya, misalnya dengan 
memberikan produk berkualitas baik dengan harga yang ekonomis dan pelayanan yang lebih baik dan ramah dibandingkan pesaingnya.

Tugas sebuah perusahaan adalah untuk memberikan kepuasan kepada pelanggan. Pelanggan yang tidak puas akan meninggalkan perusahaan dan akan menjadi pelanggan pesaing. Hal ini akan menyebabkan penurunan penjualan, menurunnya pelanggan dan mengurangi aset perusahaan yang berpotensi menimbulkan kerugian bagi perusahaan. Dengan demikian seorang pimpinan perusahaan atau pelaku bisnis harus berusaha untuk meningkatkan kepuasan pelanggan dengan melakukan sesuatu yang dapat membuat para pelanggannya merasa puas sehingga bersedia mempromosikan kepada orang-orang di sekitarnya untuk berlangganan yang sama tanpa diminta oleh pihak perusahaan. Kepuasan yang melebihi harapannya setelah mengkomsumsi produk dari perusahaan tersebut akan menjadi sebuah keuntungan bagi perusahaan.

Kepuasan pelanggan merupakan tingkat perasaan seorang pelanggan setelah membandingkan kinerja yang dirasakan terhadap harapannya (Kotler, 2005). Kepuasan pelanggan sudah menjadi tolak ukur bagi pemilik/pelaku usaha dalam mengembangkan perusahaannya. Terciptanya kepuasan pelanggan adalah langkah awal bagi perusahaan dalam membangun suatu hubungan baik dengan pelanggan. Hal ini akan menguntungkan sebuah perusahaan karena akan membentuk pelanggan yang setia (loyalty) bahkan pelanggan tersebut akan mempromosikan kepada orang lain untuk berlangganan yang sama atau yang disebut dengan word of mouth (wom) yaitu mulut ke mulut.

Mempertahankan seorang pelanggan bagi sebuah perusahaan bukanlah perkara yang mudah. Hal ini dikarenakan seorang pelaku usaha atau pimpinan usaha harus meningkatkan kepuasan bagi pelanggan. Misalnya dengan penerapan experiential marketing dan nilai pelanggan, yaitu dengan mengkonsep sebuah perusahaan agar pemasaran perusahaan meningkat. Salah satu konsep tersebut adalah seorang pemasar harus bisa mengikat pelanggan atau mempertahankan pelanggan dengan memenuhi keinginan dan kebutuhan pelanggannya.

Penilaian terhadap perusahaan setelah mengkonsumsi produknya disebut dengan nilai pelanggan. Nilai pelanggan sangat berpengaruh bagi perusahaan dalam menciptakan kepuasan pelanggan. Hal ini dikarenakan perusahaan dapat mengetahui 
kekurangan dan kelebihannya. Dengan demikian pelaku usaha akan mudah untuk memperbaiki dan mempertahankan pelanggannya karena mereka mengetahui apa yang harus diperbaiki dari kekurangan perusahaan dan apa yang harus dipertahankan dari perusahaan agar pelanggan mendapatkan kepuasan bahkan lebih dari yang diharapkan.

Berdasarkan hal-hal yang sudah dipaparkan di atas, peneliti tertarik untuk menganalisis pengaruh experiential marketing dan nilai pelanggan pada CV. Yukas Family sehingga dapat mempertahankan pelanggan dalam jangka waktu yang panjang.

\section{KAJIAN TEORI}

\section{Pemasaran}

Menurut Kotler \& Keller (2016) pemasaran adalah kegiatan mengidentifikasikan pemenuhan kebutuhan manusia dan sosial. Singkatnya adalah pertemuan kebutuhan yang saling membutuhkan.

\section{Experiential Marketing}

Experiential marketing merupakan jenis metode komunikasi tatap muka yang menimbulkan perasaan fisik dan emosional pelanggan, dimana hal tersebut menyebabkan pelanggan berharap agar relevan dan interaktif terhadap beberapa merek dan merasakan serta mengalami sepenuh hati (You-Ming, 2010).

Smilansky (2009) menyatakan bahwa experiential marketing adalah proses mengidentifikasi dan memuaskan kebutuhan pelanggan dengan aspirasi yang menguntungkan karena melibatkan komunikasi dua arah, sehingga memberikan kepribadian terhadap brand tersebut untuk bisa hidup dan menjadi nilai tambah (add value) kepada target/pelanggan. Experiential marketing terdiri dari lima modul pengalaman strategis yang merupakan dasar dari experiential marketing tersebut. Lima modul pengalaman tersebut adalah sense, feel, think, act dan relate. Kelima bentuk pengalaman tersebut merupakan lima dimensi dari experiential marketing. 


\section{Dimensi Experiential Marketing}

Menurut Dewi et al., (2015) faktor- faktor yang mempengaruhi experiential marketing adalah: 1) sense, berupa aspek yang berwujud dan dapat dirasakan oleh pelanggan melalui kelima panca indra manusia yang meliputi penglihatan, penciuman, pendengaran, peraba dan penggecapan; 2) feel, berupa strategi dan implementasi dalam mengikat pelanggan untuk senang terhadap perusahaan dan merek melalui pengalaman penyedia jasa; 3) think, berupa metode pemasaran yang bertujuan untuk mendorong pelanggan agar berfikir kreatif atas perusahaan dan merek-mereknya; 4) act, bentuk strategi yang dilakukan untuk menciptakan pengalaman pelanggan yang dihubungkan pada prilaku individu, prilaku sosial dan gaya hidup; 5) relate, berupa pengembangan perasaan yang disarankan oleh individu yang merupakan pengalaman dan dikaitkan dengan figur idaman individu, orang lain dan suatu kebudayaan.

\section{Nilai Pelanggan}

Nilai pelanggan adalah pilihan yang dirasakan seorang pelanggan dan evaluasi terhadap atribut produk, kinerja atribut dan konsekuensi yang timbul dari penggunaan produk untuk mencapai tujuan dan maksud konsumen ketika mengkonsumsi atau menggunakan produk. Adapun nilai pelanggan dan kepuasan pelanggan juga dikaitkan dengan nilai pelanggan sebagai persepsi pengalaman terhadap konsekuensi yang diinginkan dari penggunaan suatu produk tersebut. Nilai pelanggan sangat berpengaruh terhadap kepuasan pelanggan bahkan terciptanya suatu kepuasan dengan adanya nilai pelanggan karena semakin tinggi nilai pelanggan maka semakin tinggi pula kepuasan pelanggan.

Menurut Rangkuti (2003) nilai pelanggan merupakan pengkajian secara menyeluruh mengenai manfaat dari suatu produk yang didasarkan pada persepsi pelanggan atas apa yang didapat dengan biaya yang di keluarkan. Adapun menurut Tjiptono (2007) nilai pelanggan adalah tradeoff antara persepsi pelanggan terhadap kualitas atau manfaat produk dan pengorbanan yang dilakukan lewat harga yang dibayarkan. Nilai pelanggan juga didefinisikan sebagai ikatan emosional yang terjalin antara pelanggan dan produsen setelah pelanggan menggunakan produk dan jasa dari perusahaan dan mendapati bahwa produk atau jasa terebut memberi nilai tambahan. 


\section{Dimensi Nilai Pelanggan}

Menurut Tjiptono (2005) dimensi nilai terdiri dari 4, yaitu: 1) emotional value yaitu utilitas yang berasal dari perasaan atau emosi positif yang ditimbulkan dari mengkonsumsi produk; 2) sosial value yaitu utilitas yang diperoleh dari kemampuan produk untuk meningkatkan konsep dari sosial konsumen; 4) quality/performance value yaitu utilitas yang didapat dari produk karena reduksi biaya jangka pendek dan biaya jangka panjang; 4) price/value of money yaitu utilitas yang diperoleh dari persepsi terhadap kinerja yang diharapkan dari suatu produk atau jasa.

\section{METODE PENELITIAN}

Penelitian ini dilaksanakan di CV. Yukas Family Kabupaten Sukabumi. Metode yang digunakan dalam penelitian ini deskriptif dan asosiatif. Menurut Sugiyono (2013) metode penelitian deskriptif adalah penelitian yang dilakukan untuk mengetahui nilai variabel mandiri, baik hanya pada suatu variabel atau lebih tanpa membuat perbandingan. Adapun penelitian asosiatif merupakan penelitian yang bertujuan untuk mengetahui hubungan antara dua variabel atau lebih.

\section{HASIL PENELITIAN}

\section{Uji Validitas}

Uji validitas adalah alat ukur untuk mengukur apa yang sehartusnya diukur sehingga suatu penelitian yang menggunakan kuesioner sebagian besar pengukurannya perlu diuji validitasnya. Syarat minimum untuk dianggap memenuhi syarat adalah $r=$ 0,3, jadi jika korelasi antara butir dengan skor total kurang dari 0,3 maka butir dengan instrument dinyatakan tidak valid.

Data yang dianalisis diperoleh dari hasil kuesioner yang dihitung dengan menggunakan software SPSS 24. Hasil analisis dapat dilihat pada tabel berikut ini:

Tabel 1.

Hasil Uji Validitas Item Variabel Experiential Marketing

\begin{tabular}{cccc}
\hline No. Item & r-Hitung & r-Kritis & Keputusan \\
\hline 1 & 0,853 & 0,3 & Valid \\
2 & 0,385 & 0,3 & Valid \\
3 & 0,728 & 0,3 & Valid \\
4 & 0,720 & 0,3 & Valid \\
5 & 0,476 & 0,3 & Valid \\
\hline
\end{tabular}

(Sumber: Hasil Pengolahan Data, 2019) 
Tabel 2.

Hasil Uji Validitas Item Variabel Nilai Pelanggan

\begin{tabular}{cccc}
\hline No. Item & r-Hitung & r-Kritis & Keputusan \\
\hline 1 & 0,800 & 0,3 & Valid \\
2 & 0,471 & 0,3 & Valid \\
3 & 0,897 & 0,3 & Valid \\
4 & 0,847 & 0,3 & Valid \\
\hline
\end{tabular}

(Sumber: Hasil Pengolahan Data, 2019)

Tabel 3.

Hasil Uji Validitas Item Variabel Kepuasan Pelanggan

\begin{tabular}{cccc}
\hline No. Item & r-Hitung & r-Kritis & Keputusan \\
\hline 1 & 0,780 & 0,3 & Valid \\
2 & 0,786 & 0,3 & Valid \\
3 & 0,759 & 0,3 & Valid \\
4 & 0,626 & 0,3 & Valid \\
5 & 0,662 & 0,3 & Valid \\
\hline
\end{tabular}

(Sumber: Hasil Pengolahan Data, 2019)

\section{Uji Reabilitas}

Tabel 4.

Hasil Uji Reliabilitas Item Variabel Kepuasan Pelanggan

\begin{tabular}{ccc}
\hline \multicolumn{3}{c}{ Reliability Statistics } \\
\hline Cronbach's Alpha & Cronbach's Alpha Based on Standardized Items & Nof Items \\
\hline, 771 &, 771 & 5 \\
\hline
\end{tabular}

(Sumber: Hasil Pengolahan Data, 2019)

\section{Koofesien Korelasi Ganda}

Tabel 5.

Koefisien Korelasi antara Experiential Marketing dan Nilai Pelanggan terhadap Kepuasan Pelanggan

\begin{tabular}{ccccc}
\hline \multicolumn{4}{c}{ Model Summary } \\
\hline & Rodel & R Square & Adjusted R Square & Std. Error of the Estimate \\
\hline 1 &, $803^{\text {a }}$ &, 645 &, 637 & 2,490 \\
\hline a. & Predictors: (Constant), Nilai & Pelanggan, Experiential Marketing
\end{tabular}
(Sumber: Hasil Pengolahan Data, 2019)

Berdasarkan perhitungan pada tabel 5, dapat diketahui bahwa korelasi variabel experiential marketing dan nilai pelanggan terhadap kepuasan pelanggan adalah sebesar 0,803 (nilai R). 


\section{Koefisien Determinasi}

Bentuk perhitungan yang digunakan untuk mendapatkan hasil koefisien determinasi adalah sebagai berikut:

$$
\begin{aligned}
\mathrm{r} & =0,803 \\
\mathrm{Kd} & =(0,803)^{2} \times 100 \% \\
\mathrm{Kd} & =0,644 \times 100 \% \\
\mathrm{Kd} & =64,4 \%
\end{aligned}
$$

Berdasarkan perhitungan koefesien determinasi yang telah peneliti lakukan, maka dapat disimpulkan bahwa pengaruh experiential marketing dan nilai pelanggan terhadap kepuasan pelanggan yaitu lemah.

Perhitungan regresi linier berganda yang dilakukan peneliti menggunakan bantuan software SPSS 24. Adapun hasil perhitungan tersebut dapat dilihat pada tabel berikut:

Tabel 6.

Hasil Pengujian Secara Simultan (Uji F)

\begin{tabular}{clccccc}
\hline \multicolumn{7}{c}{ ANOVA $^{\mathbf{a}}$} \\
\hline \multirow{2}{*}{ Model } & & Sum of Square & Df & Mean Square & F & Sig. \\
\cline { 2 - 7 } & Regression & 979,608 & 2 & 489,804 & 78,984 &, $000^{\mathrm{b}}$ \\
\cline { 2 - 7 } & Residual & 539,514 & 87 & 6,201 & & \\
\cline { 2 - 6 } & Total & 1519,122 & 89 & & & \\
\hline
\end{tabular}

a. Dependent Variable: Kepuasan Pelanggan

b. Predictors: (Constant), Nilai Pelanggan, Experiential Marketing

(Sumber: Hasil Pengolahan Data, 2019)

\begin{tabular}{|c|c|c|c|c|c|c|}
\hline \multicolumn{7}{|c|}{ Coefficients $^{a}$} \\
\hline & \multirow[b]{2}{*}{ Model } & \multicolumn{2}{|c|}{ Unstandardized Coefficients } & \multirow{2}{*}{$\begin{array}{c}\text { Standardized Coefficients } \\
\text { Beta }\end{array}$} & \multirow[b]{2}{*}{$\mathbf{t}$} & \multirow[b]{2}{*}{ Sig. } \\
\hline & & $\mathbf{B}$ & Std. Error & & & \\
\hline \multirow[t]{3}{*}{1} & (Constant) & 28,483 & 1,455 & & 19,569 &, 000 \\
\hline & $\begin{array}{l}\text { Experiential } \\
\text { Marketing }\end{array}$ &,- 395 & 132 &,- 342 & $-2,997$ & ,004 \\
\hline & $\begin{array}{c}\text { Nilai } \\
\text { Pelanggan }\end{array}$ &,- 592 & ,136 &,- 496 & $-4,342$ &, 000 \\
\hline
\end{tabular}

\section{Regresi Linear Berganda}

Tabel 7.

Hasil Perhitungan Regresi Linear Berganda 
Berdasarkan hasil tabel 7, maka dapat diketahui nilai dari persamaan regresi linear berganda adalah sebagai berikut:

$$
\begin{array}{ll}
\mathrm{a} & =28483 \\
\mathrm{~b}_{1} & =-0,342 \\
\mathrm{~b}_{2} & =-0,496
\end{array}
$$

Bentuk persamaan regresi linear berganda untuk dua predictors yaitu experiential marketing dan nilai pelanggan adalah sebagai berikut:

$$
Y^{*}=28.483+-0,342 X_{1}+-0,496 X_{2}
$$

Berdasarkan persamaan di atas, maka dapat diketahui bahwa terdapat pengaruh positif antara experiential marketing $\left(\mathrm{X}_{1}\right)$ dan nilai pelanggan $\left(\mathrm{X}_{2}\right)$ terhadap kepuasan pelanggan (Y).

Persamaan di atas menunjukkan bahwa kepuasan pelanggan pada CV. Yukas Family di Kabupaten Sukabumi akan meningkat jika experiential marketing $\left(\mathrm{X}_{1}\right)$ dan nilai pelanggan $\left(\mathrm{X}_{2}\right)$ ditingkatkan.

\section{PEMBAHASAN}

Kepuasan merupakan perasaan berupa rasa senang atau kecewa seseorang yang muncul setelah membandingkan antara persepsi atau kesannya terhadap kinerja atau hasil suatu produk dan harapan-harapannya. Jika kinerja dibawah harapan, pelanggan tidak puas dan sebaliknya jika kinerja memenuhi dan melebihi harapan maka konsumen akan merasa puas. Apabila perusahaan memfokuskan pada kepuasan tinggi maka para konsumen yang kepuasannya hanya pas akan mudah untuk berubah pikiran bila mendapat tawaran yang lebih baik. Sedangkan konsumen yang amat puas lebih sukar untuk mengubah pilihannya (Hadiwidjaja \& Dharmayanti, 2014).

Experiential marketing merupakan salah salah satu konsep marketing yang dapat digunakan untuk mempengaruhi emosi konsumen karena tidak hanya sekedar memberikan informasi dan peluang pada pelanggan untuk memperoleh pengalaman atas keuntungan yang didapat tetapi juga membangkitkan emosi dan perasaan yang berdampak terhadap pemasaran, khususnya penjualan (Andreani, 2007). Experiential marketing dinilai sangat efektif karena sejalan dengan perkembangan zaman. Para 
pengusaha lebih menekankan kualitas service dan sesuatu yang menjadi nilai tambah bagi perusahaan untuk membedakan bisnisnya dengan bisnis yang lain (kompetitor).

Nilai pelanggan merupakan selisih antara total manfaat yang diperoleh pelanggan atau konsumen dengan total pengorbanan yang dilakukan. Komponen nilai pelanggan meliputi manfaat dan pengorbanan. Manfaat dan pengorbanan yang diterima pelanggan terdiri dari manfaat dan pengorbanan fungsional, manfaat dan pengorbanan sosial serta manfaat dan pengorbanan emosional (Wahyuningsih, 2004).

Hasil penelitian ini menunjukkan bahwa experiential marketing pada CV. Yukas Family Kabupaten Sukabumi terbukti dapat meningkatkan kepuasan pelanggan. Para pelanggan CV. Yukas Family di Kabupaten Sukabumi menyatakan puas terhadap penerapan experiential marketing pada perusahaan ini. Hal ini sejalan dengan penelitian Suyanto \& Yurdatila (2013) yang menunjukkan bahwa konsumen puas terhadap penerapan experiential marketing yang dinilai sudah baik.

Penilaian pelanggan terhadap CV. Yukas Family sudah dapat dikatakan baik dalam menciptakan kepuasan pelanggan. Menurut Restuadhi et al., (2014) nilai pelanggan berkaitan dengan proses memberi dan menerima yang dialami oleh pelanggan. Jika manfaat yang diterima oleh pelanggan lebih tinggi daripada pengorbanan yang dikeluarkan maka perusahaan sudah berhasil menciptakan nilai pelanggan. Sedangkan jika manfaat yang diterima pelanggan tersebut lebih kecil daripada pengorbanan yang dikeluarkan maka pelanggan cenderung akan merasa dirugikan dan pada akhirnya kecewa. Dengan demikian berarti perusahaan gagal menciptakan nilai pelanggan pada produk yang ditawarkannya kepada pelanggan.

Kepuasan Pelanggan terhadap kualitas produk, harga produk, kualitas pelayanan, emosi, biaya dan kemudahan yang diberikan oleh CV. Yukas Family dapat dinyatakan baik. Menurut Panjaitan \& Yuliati (2016) bahwa pelayanan yang berkualitas berperan penting dalam membentuk kepuasan konsumen, selain itu juga erat kaitannya dalam menciptakan keuntungan bagi perusahaan. Semakin berkualitas pelayanan yang diberikan oleh perusahaan maka kepuasan yang dirasakan oleh pelanggan akan semakin tinggi. 


\section{SIMPULAN}

Penerapan experiential marketing pada CV. Yukas Family Kabupaten Sukabumi terbukti dapat meningkatkan kepuasan pelanggan. Adapun pada nilai pelanggan sudah dapat dikatakan baik dalam menciptakan kepuasan pelanggan. Kepuasan Pelanggan terhadap kualitas produk, harga produk, kualitas pelayanan, emosi, biaya dan kemudahan dapat dinyatakan baik.

Experiential marketing dan nilai pelanggan secara parsial memiliki pengaruh terhadap kepuasan pelanggan pada CV. Yukas Family di Kabupaten Sukabumi. Adapun secara simultan, experiential marketing dan nilai pelanggan memiliki pengaruh yang positif dan signifikan terhadap kepuasan pelanggan. Namun setelah pengujian, terdapat faktor lain yang tidak diteliti dalam penelitian ini yang juga turut mempengaruhi kepuasan pelanggan. Dengan demikian, pengaruh experiential marketing dan nilai pelanggan terhadap kepuasan pelanggan tergolong lemah.

\section{DAFTAR PUSATAKA}

Andreani, F. (2007). Experiential Marketing (Sebuah Pendekatan Pemasaran). Jurnal Manajemen Pemasaran, 2(1), 1-8

Dewi, R. K., Kumadji, S., \& Mawardi, M. K. (2015). Pengaruh Experiential Marketing terhadap Kepuasan Pelanggan dan Dampaknya pada Loyalitas Pelanggan (Survei pada Pelanggan Tempat Wisata Jawa Timur Park 1 Kota Wisata Baru). Jurnal Administrasi Bisnis, 28(1), 1-6

Hadiwidjaja, R. S., \& Dharmayanti, D. (2014). Analisa Hubungan Experiential Marketing, Kepuasan Pelanggan, Loyalitas Pelanggan Starbucks Coffee di Surabaya Town Square. Jurnal Strategi Pemasaran, 2(2), 1-11

Kotler, P., \& Keller, K. L. (2016): Marketing Management, 15th Edition. New Jersey: Pearson Pretice Hall, Inc

Panjaitan, J. E., \& Yuliati, A. L. (2016). Pengaruh Kualitas Pelayanan terhadap Kepuasan Pelanggan pada JNE Cabang Bandung. DeReMa Jurnal Manajemen, 11(2), 265-289

Rangkuti, F. (2003). Bisnis Plan Teknik Membuat Perencanaan Bisnis dan Analisis Kasus. Jakarta: PT. Gramedia Pustaka Utama

Restuadhi, Y., Farida, N., \& Budiatmo, A. (2014). Pengaruh Kualitas Pelayanan, Nilai Pelanggan dan Kepuasan Pelanggan terhadap Loyalitas Pelanggan Hotel Siliwangi Semarang. Jurnal Ilmu Administrasi Bisnis S1 Undip, 3(2), 40-51

Smilansky, S. (2009). Experiential Marketing: A Prectical Guide Interactive to Brand Experiences. India: Replika Press

Sugiyono, S. (2013). Metode Penelitian Pendekatan Kuantitatif, Kualitatif dan R\&D. Bandung: Alfabeta 
Tjiptono, F. (2005). Pemasaran Jasa. Malang: Bayumedia Publishing Tjiptono, F. (2007). Pemasaran Jasa. Malang: Bayumedia Publishing

Wahyuningsih, W. (2004). Customer Value: Concept, Operationalization and Outcome. Jurnal Manajemen Usahawan Indonesia, 33(8), 3-10

You-Ming, C. (2010). Study on Impact of Experiential Marketing and Customer Satisfaction Based on Relationship Quality. The International Journal of Organizational Innovation, 3(1), 189-209 